\title{
CACHAÇA
}

\section{PESQUISA E NOVOS NEGÓCIOS NA REDESCOBERTA DESSE AGUARDENTE SECULAR}

Com quase quinhentos anos, a história da cachaça confunde-se com a do Brasil. Primeira bebida destilada das Américas - criada antes do pisco peruano e da tequila mexicana-, é cada vez mais valorizada por um público sofisticado, disposto a pagar preços de malte escocês envelhecido 12 anos. Sua imagem tipicamente popular adquiriu o charme de uma bebida de qualidade, genuinamente brasileira. A transformação deve-se a fatores de natureza econômica e cultural e a iniciativas de produtores e do Estado para expandir seu consumo. Uma das iniciativas para fortalecer a cadeia produtiva da cachaça foi feita pela Câmara Setorial da Cachaça, do Ministério da Agricultura, composta por representantes do setor privado e do governo. O trabalho da Câmara resultou na elaboração da Agenda Estratégica 2010 - 2015 para Cachaça. Publicada em 2011, a Agenda estabelece um plano de ação para diversas áreas envolvidas nesta cadeia produtiva como legislação, inteligência competitiva, levantamento da produção e estoques de aguardente de cana e cachaça, pesquisa e desenvolvimento, entre outras. De acordo com Jairo Martins da Silva, superintendente-geral da Fundação Nacional da Qualidade (entidade sem fins lucrativos, ligada ao setor empresarial), a Agenda deve

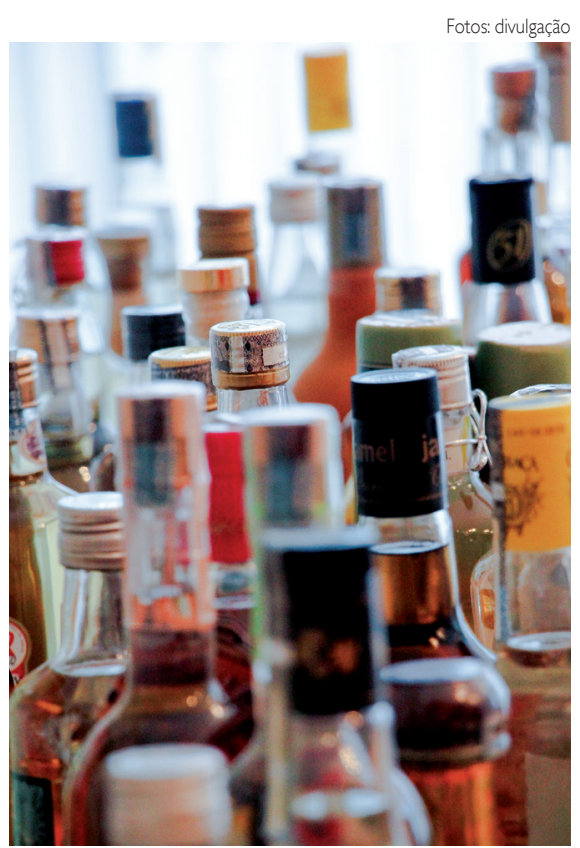

No Brasil existem 40 mil produtores e quatro mil marcas de cachaça

fortalecer a imagem da cachaça como um produto genuinamente brasileiro, melhorar sua qualidade, além de também coibir a produção e o comércio de produtos clandestinos.

Para Martins, que há alguns anos trabalha na divulgação da cachaça brasileira na Europa, os produtores têm dado mais importância à qualidade. "Isso é muito positivo, especialmente neste momento em que vamos receber grande número de público estrangeiro durante a Copa do Mundo e os Jogos Olímpicos", acredita. A divulgação correta da nossa bebida mais famosa pode abrir portas para aumentar a exportação do produto. Em 2013, a exportação foi de nove milhões de litros, para 59 países, número $12 \%$ maior do que no ano anterior, segundo informaçōes do Instituto Brasileiro da Cachaça (Ibrac). Os maiores importadores são Alemanha, Estados Unidos e Portugal. "Podemos vender mais para outros países. A exportação da cachaça não chega a $1 \%$ do que é produzido. Esse é um desafio", aponta Jairo Martins.

CAPACITAÇÃo O novo status da cachaça já se reflete no mercado de trabalho, ao gerar demandas por novos profissionais. Por meio de uma parceria com o Ibrac, o Senac São Paulo oferece, desde 2006, um curso para formar o sommelier de cachaça. Assim como o especialista em vinho, ele seleciona bons produtos, elabora cartas, serve clientes da maneira correta, sugerindo diferentes tipos de aguardentes com possibilidades de degustação e harmonização. $\mathrm{O}$ sommelier de cachaça também desenvolve ações de comunicação que possam contribuir para a apreciação e disseminação da cultura cachacista. "Tínhamos um problema no setor de serviços. Depois de organizar toda a cadeia produtiva para gerar um produto de qualidade, na hora de servir a bebida o garçom não estava preparado para atender, para explicar as peculiaridades da nossa cachaça. Isso prejudicava muito a imagem do produto porque a classe média alta, em especial, consome a aguardente nos restaurantes", conta Martins, que também é professor de tecnologia de bebidas, da Universidade Anhembi Morumbi. 
PESQUISAS A universidade tem tido um papel importante no aprimoramento da cachaça brasileira. Uma das pesquisas que melhoraram a qualidade do produto foi a descoberta de uma levedura natural que acelera a fermentação e dá cor e aroma especial à bebida. "Os produtores da nossa região reclamavam que perdiam toda a produção da cachaça na etapa da fermentação porque a cachaça ficava muito ácida”, conta a agrônoma Rosane Schwan, da Universidade Federal de Lavras (UFLA). Depois de um longo trabalho de seleção, que envolveu a pesquisa em mais de 1,2 mil leveduras, a equipe da Rosane chegou a quatro tipos que revelaram os melhores resultados.

A UFLA-CA11, uma dessas leveduras, já está sendo comercializada para produtores de cachaça artesanal. "Só é considerada artesanal a cachaça produzida com caldo de cana-de-açúcar in natura, sem adição de produtos químicos. A destilação deve ser feita em alambiques de cobre”, explica Rosane. A aguardente industrial pode ser de caldo de cana ou melaço, permite o uso de nutrientes, como sulfato de amônia e ureia, e a destilação pode ser feita em recipientes de aço inox.

A levedura desenvolvida na UFLA acelera o processo de fermentação (ver box) e, devido à tolerância a altas concentraçôes de etanol, produz mais cachaça a partir da mesma quantidade de cana, quando comparada às leveduras disponíveis no mercado. Ela propiciaaindaum sabor frutal earoma diferenciado, resultantes da produção de alguns álcoois superiores. Outra vantagem da UFLA-CA11 é que ela não produz os chamados aldeídos na mesma quantidade que as leveduras utilizadas pela indústria atual. Eles são responsáveis pela desagradável ressaca do dia seguinte. "A maior aceitação da cachaça tem a ver com a melhoria da qualidade da bebida, uma bebida sem metanol, menos aldeído e outras metabólicos tóxicos", acredita Rosane Schwan. A nova levedura também é mais resistente aos contaminantes que porventura estejam presentes na cana.

NOVOS SABORES Estimativas do Ibrac apontam que existem cerca de quatro mil marcas e 40 mil produtores no Brasil, sendo 99\% de pequeno porte. Thiago Nego, de 30 anos, é um deles. Ele produz artesanalmente a cachaça Samba Nego. São apenas 30 garrafas por mês. A bebida é um composto de aguardente feito com erva-doce, caramelo e limão siciliano. Thiago e mais dois amigos sempre gostaram $\mathrm{da}$ bebida, mas sentiam falta de um produto diferente. "A gente sempre escutava as pessoas dizerem que gostariam de tomar cachaça, mas que era uma bebida muito forte. Queríamos produzir uma cachaça que agradasse esse perfil de consumidor", diz. "Demoramos uma ano e meio para chegar à receita ideal”, conta. A distribuiçãoo é feita apenas em bares e restaurantes de alguns bairros da capital paulista como Pinheiros, Vila Madalena e Perdizes. "Queremos preservar a qualidade com preço baixo. Nossa meta é aumentar a produção para 180 garrafas mensais". Todas trazem no rótulo um recado para velhos e novos consumidores: "Uma homenagem aos brasileiros que estão em busca de novos sabores e combinações".

Mariana de Castro Alves

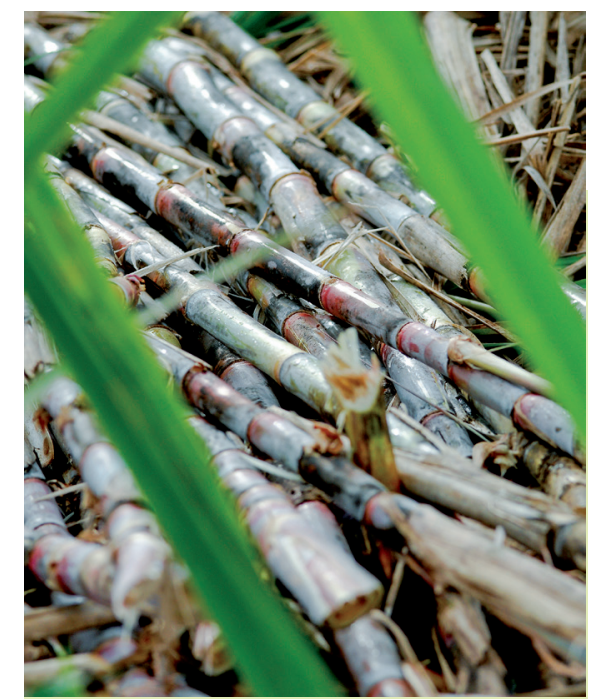

Cachaça artesanal exige corte manual da cana

\section{NO CORAÇÃo}

\section{DA MISTURA}

Para fabricação da cachaça artesanal, a cana-de-açúcar é cortada manualmente, nos meses de maio e junho. Depois da moagem, o caldo é separado do bagaço e, em seguida, decantado e filtrado. Na dorna para fermentação, uma levedura converte os açúcares em álcool etílico e gás carbônico e são formados os compostos orgânicos voláteis, responsáveis pelo sabor da cachaça. Em alambiques de cobre o líquido é destilado e separado em três produtos conhecidos como cabeça, coração e cauda. 0 que é aproveitado está justamente no coração da mistura. Depois a cachaça é estocada em barris de madeira onde outras reações químicas ocorrem, aprimorando o aroma, cor e sabor da bebida. 